\title{
Multi-point Analysis of Economic, Environmental, Static and Dynamic Dispatching of an Energy Mix in the Presence of STATCOM by the U-NSGA-III Genetic Algorithm
}

\author{
Arouna Oloulade ${ }^{1}$, Adolphe Moukengue Imano², François Xavier Fifatin ${ }^{3}$, \\ Auriole Prudence Omoremy ${ }^{1}$, Amédée Ganye ${ }^{1}$, Ramanou Badarou ${ }^{3}$, Antoine Viannou ${ }^{4}$, \\ Mahamoud Tanimomon ${ }^{1}$ \\ ${ }^{1}$ Electrotechnic, Telecommunications and Informatics Laboratory (LETIA), University of Abomey-Calavi, Abomey-Calavi, Benin \\ ${ }^{2}$ Electronic, Electrotechnic, Automatic, Telecommunications Laboratory (LEEAT), University of Douala, Douala, Cameroon \\ ${ }^{3}$ Polytechnic School of Abomey-Calavi (EPAC), University of Abomey-Calavi, Abomey-Calavi, Benin \\ ${ }^{4}$ Laboratory of Thermophysic Characterization of Materials and Energy Mastering, University of Abomey-Calavi, Abomey-Calavi, Benin \\ Email address: \\ olouarou@yahoo.fr (A. Oloulade), moukangueimano@gmail.com(A. Moukengue Imano), moukangueimano@gmail.com(F-X. Fifatin), \\ olouarou@yahoo.fr(M. Taninomon), aurioleomoremy@gmail.com(A.P. Omoremy), ramanou@yahoo.fr(R.Badarou), \\ avianou@yahoo.fr(A.Vianou)
}

\section{To cite this article:}

Arouna Oloulade, Adolphe Moukengue Imano, François Xavier Fifatin, Auriole Prudence Omoremy, Amédée Ganye, Ramanou Badarou, Antoine Viannou, Mahamoud Tanimonon. Multi-point Analysis of Economic, Environmental, Static and Dynamic Dispatching of an Energy Mix in the Presence of STATCOM by the U-NSGA-III Genetic Algorithm. American Journal of Electrical Power and Energy Systems. Vol. 9, No. 5, 2020, pp. 74-81. doi: 10.11648/j.epes.20200905.11

Received: May 18, 2020; Accepted: June 4, 2020; Published: September 21, 2020

\begin{abstract}
In an energy environment with multiple production sources, operators are generally confronted with the optimal choice of sources which minimizes polluting gas emissions, losses and marginal production costs while meeting the contractual requirements for maintaining voltage in the ranges required. The present work consisted of optimizing an energy mix in the presence of multi-STATCOM in an interconnected network. Indeed, the (DEE) is a concrete real time problem in electrical energy production systems. This paper shows the impact of STATCOM on static DEE (DEES) and on dynamic DEE (DEED) using the modern genetic algorithm of type U-NSGA-III, which is based on non-dominance sorting. The optimal positioning of two STATCOMs in the application network associated with dynamic dispatching has contributed to the reduction of the total production cost, toxic gas emissions, active losses and then to the improvement of the voltage profiles and the transit of power in the branches. It is observed that the combination of DEED with the optimal positioning of FACTS in an interconnected network constitutes an efficient technico-ecological means to act in the direction of reduction on the triplet consisting of (gas emissions, losses, production cost). The relevance of the results obtained compared to the real case of operating the CEB's interconnected network, justifies the performance of the algorithmic tools developed in the context of this work.
\end{abstract}

Keywords: Environmental Economic Dispatching, Dynamic, Static, STATCOM, UNSGA-III, Multi-criteria Optimization, Interconnected Network, Transmission Network

\section{Introduction}

The intrinsic characteristics of electrical energy are such that it must be produced, distributed, consumed and accounted at the same time [1]. Its management is totally different from that of other forms of energy.

With the increasing evolution of demography, industrialization and urbanization, we are witnessing a growth in demand for electrical energy. However, this is mainly produced by thermal power plants running on fossil fuels. Thus, the ever growing growth of charges on electrical networks implicitly induces the growth of the emission of gases such as $\mathrm{CO}_{2}$ and $\mathrm{SO}_{2}$ which have very harmful effects on human health. These gases not only affect human health 
but also have negative impacts on plants, animals and biodiversity [2]. Since the awareness of the public authorities to reduce the emission of harmful gases and the tendency of disintegration of electrical systems which are generalizing to allow the insertion of decentralized production to the effect of improving the efficiency of these systems, several techniques for reducing air pollution have been initiated. These include the installation of pollution control equipment, the use of low-emission performance fuels and the optimization of dispatching so as to reduce gas emissions while satisfying the demand for electrical energy at low cost for the customers [3]. In a context where several generators inject into an interconnected electrical network, determining the optimal configuration of energy generators which will make it possible, among other things, to minimize the cost of fuels and the emission of gases from internal combustion of heat engines is a source of major concern for managers of electrical systems [4]. Optimizing the energy mix is often one of the most economically and practically accessible solutions for regulating toxic gas emissions and reducing excessive fuel costs.

The DEES consists in distributing the production of electrical energy between the various power stations of the network in order to satisfy the demand at a precise moment. DEED, on the other hand, consists in distributing this production between the power stations of the network in order to satisfy demand over a period of time, for example 24 hours or a week. In the network, demand is not constant, so production must constantly adapt to this variation. To solve this problem, the DEED is formulated by taking practical constraints on the generators. It is a complex problem which requires the use of robust optimization methods. Several authors have already addressed this problem. Wu et al. [5] used the MODE (Multi-Objective Differential Evolution) to solve the problem of DEES. A selection mechanism based on fuzzy logic has been developed in order to choose the optimal solution among the solutions of the final Pareto front. They performed their tests on IEEE standard networks 30 nodes and 118 nodes. Jiang et al., In [6], have optimized DEES on five different networks and by considering different combinations of practical constraints. To this end, they have developed a new algorithm (the HPSO-GSA) having the attributes of the PSO (Particle Swarm Optimization) and the GSA (Gravity Search Algorithm). The results they obtained were satisfactory, but the mono-objective formulation of the problem did not allow an individual assessment of each objective. Ngoffe Stève PERABI et al. [7] used the observation corridor method which is an evolutionary algorithm to optimize DEED. The objectives considered are the minimization of the cost of fuel, the emission of $\mathrm{NO}_{2}$ and the emission of $\mathrm{SO}_{2}$. The results obtained were satisfactory but could be better by acting on the parameters of the network.

With the appearance of FACTS (Flexible Alternating Current Transmission Systems) devices in the last decade, their use in electrical energy transmission systems has increased. These are alternating current transmission systems incorporating controllers based on power electronics. They are very fast devices made up of static switches generally allowing the control of power flow [8]. They can facilitate the control of the flow of energy, the improvement of the transfer of power, the increase of the reactive reserve of the generators, the reduction of the variations of tension and losses [9]. Some authors have worked on optimizing dispatching in the presence of these devices in order to obtain better results. This is the case of Suresh et al. [10] who integrated the Generalized Unified Power Flow Controller (GUPFC) into the DEE problem with the aim of reducing the total cost of production, active losses and gas emissions. The algorithm they used is the NSUDTPSO (Non-dominated Sorting Uniformly Distributed Two-stage Particle Swarm Optimization). Tests carried out on IEEE 30-bus networks have shown that with the insertion of this FACTS, active losses in the network are reduced as well as the total production cost and gas emissions. In 2016, Vijayaraj et al. [11] did the same work as [10] but using the improved bat algorithm (IAB). The tests were carried out on the 30 -node IEEE network with and without UPFC. Analysis of the results showed that in the presence of GUPFC, active losses in the network are smaller than in the absence of GUPFC. In addition, there is an improvement in the stability of the network. However, an analysis of the literature shows that neither the performance of STATCOM in a DEES or DEED problem nor its economic advantages in such problems have not been tested in any article. This paper therefore presents an analysis of the impact of STATCOM on the results of DEES and DEED in a transmission network.
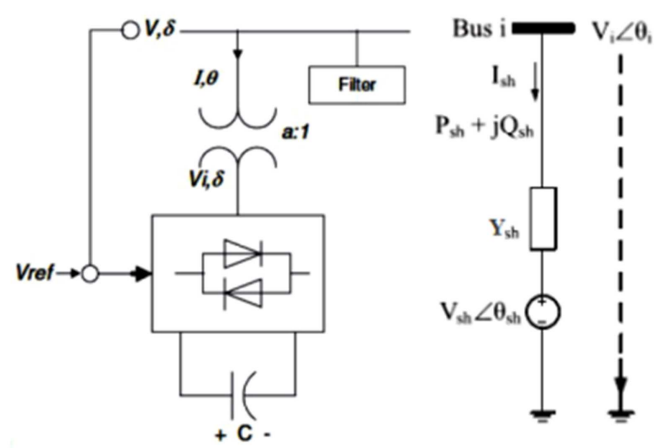

Figure 1. (a) Basic structure of a STATCOM Figure 1 (b) Equivalent circuit of a STATCOM.

In Benin, the energetic mix system has been improved in recent years by the construction and operation of a $120 \mathrm{MW}$ thermal power plant in Cotonou and the construction of another $80 \mathrm{MW}$ thermal power plant in Lomé, Togo. In fact, the electrical system was powered by two power stations. The imperfections noted by the dispatching managers built by the CEB to configure the most optimal plants in terms of cost and reduction of hazardous emissions do not allow optimal management of the system. Indeed, it is very complex today to identify the period, the power and the types of plants to be injected according to the demand for an energy management minimizing the operating costs and the emissions. In addition, as the demand for energy increases, the network 
becomes more complex to control and this results in loop flows, various failures (undervoltage, overvoltage, etc.) and more losses [12]. To use the existing transmission system efficiently, by transmitting maximum power through the transmission lines, FACTS devices including the STATCOM (Static Synchronous Compensator) are often suitably integrated into the electricity network [6]. The installation of FACTS (in particular STATCOM in our case) improves the flow of active power by providing reactive power to transmission lines [13]. This also results in a reduction in losses of active power and an improvement in the voltage profile [14]. In the literature, several methods have been developed by scientists for solving the problem of DEE in the presence of FACTS. In our work, we will use the genetic algorithm U-NSGA-III for the optimization of DEE in the presence of STATCOM in the transmission network of the CEB.

\section{Statcom Modeling}

There are two mathematical models of STATCOM: the static model and the dynamic model. The static model is based on algebraic equations, while the dynamic model is based on simulations over time [15]. In the context of this work, only the static model of STATCOM will be used for its insertion into the power flow program.

A STATCOM produces a balanced set of sinusoidal voltage at the fundamental frequency with a phase angle and amplitude that change rapidly according to the needs of the system [16].

The figure 1-a shows the schematic diagram of the STATCOM. It consists of a coupling transformer, a voltage converter and a controlled voltage source. It can absorb or inject reactive power to and from the node where it is connected.

1. If $\mathrm{Vi}<\mathrm{Vsh}$, the STATCOM supplies reactive power to the network (capacitive mode).

2. When $\mathrm{Vi}>\mathrm{Vsh}$ the STATCOM absorbs reactive power from the network (inductive mode). The amount of reactive power injected or absorbed is proportional to the voltage difference $\Delta \mathrm{V}$ between $\mathrm{Vi}$ and Vsh [15].

The active and reactive powers supplied by the STATCOM to the network are given by:

$$
\begin{gathered}
P_{s h-i}=V_{s h}^{2} G_{s h}-V_{s h} V_{i}\left[G_{s h} \cos \left(\delta_{s h}-\delta_{i}\right)+B_{s h} \sin \left(\delta_{s h}-\delta_{i}\right)\right] \\
Q_{s h-i}=-V_{s h}^{2} B_{s h}+V_{s h} V_{i}\left[G_{s h} \sin \left(\delta_{s h}-\delta_{i}\right)+B_{s h} \cos \left(\delta_{s h}-\delta_{i}\right)\right]
\end{gathered}
$$

The reactive power transmitted by the network to STATCOM (exchanged power) is expressed by:

$$
Q_{i-s h}=-V_{i}^{2} B_{s h}+V_{s h} V_{i}\left[B_{s h} \cos \left(\delta_{i}-\delta_{s h}\right)+G_{s h} \sin \left(\delta_{i}-\delta_{s h}\right)\right]
$$

With:

$V_{i} \angle \delta_{i}$ : complex tension at node $\mathrm{i}$

$V_{s h} \angle \delta_{s h}$ : complex tension of STATCOM

$Y_{s h}=\frac{1}{Z_{s h}}=G_{s h}+j B_{s h}:$ shunt admittance of the

STATCOM transformer

$P_{s h}+j Q_{s h}:$ apparent power of STATCOM

3. Formulation of the Problem of Optimizing DEES and DEED in the Presence of Statcom

In the case of the multi-objective problem of DEE, we have three objectives namely:

1. The cost of production

2. The amount of toxic gases

3. Losses in the network

A Cost functions

1. Cost of production function

By not considering the opening effect of the valves, the total production cost is expressed by [4]:

$$
F_{1}=\sum_{t=1}^{T} \sum_{i=1}^{N_{g}} a_{i} P_{i, t}^{2}+b_{i} P_{i, t}+c_{i}
$$

Or

1. $F_{1}=$ total production cost in $\$ / \mathrm{h}$

2. $P_{i, t}=$ active power generated by plant $\mathrm{i}$ at interval $\mathrm{t}$ in MW

3. $a i, b i$ and $c i=$ coefficients of the cost function of generator $\mathrm{i}$
4. $T=$ total number of dispatching intervals in the relevant dispatching period

5. $N g=$ total number of plants in the network.

2. Toxic gas emission function

The gas emissions function is expressed as follows [4] without considering the opening effect valves:

$$
F_{2}=\sum_{t=1}^{T} \sum_{i=1}^{N_{g}} \alpha_{i} P_{i, t}^{2}+\beta_{i} P_{i, t}+\gamma_{i}
$$

Where

1. $F_{2}=$ total emission of toxic gases $\left(\mathrm{CO}_{2}\right)$ in $\mathrm{kg} / \mathrm{h}$

2. $P_{i, t}=$ active power generated by plant $\mathrm{i}$ at interval $\mathrm{t}$ in MW

3. $T=$ total number of dispatching intervals in the relevant dispatching period

4. $N g=$ total number of plants in the network.

3. Network loss function

The function for minimizing active losses in the network is expressed as follows:

$$
F_{3}=\sum_{t=1}^{T} P_{L, t}
$$

Where $P_{L, t}$ is the active loss in the network at the interval t. Based on Kron's formula [12] [13], $P_{L, t}$ can be expressed as follows: 


$$
P_{L, t}=\sum_{i=1}^{N_{g}} \sum_{j=1}^{N_{g}} P_{i, t} B_{i, j} P_{j, t}+\sum_{i=1}^{N_{g}} B 0_{i} P_{i, t}+B 00
$$

With:

1. $F_{3}=$ total active losses in the network in MW

2. $P_{i, t}=$ active power generated by plant $\mathrm{i}$ at interval $\mathrm{t}$ in MW

3. $B_{i, j}, B 0_{i}$ and $\mathrm{B} 00=$ coefficients of the loss matrix $\mathrm{B}$

4. $T=$ total number of dispatching intervals in the relevant dispatching period

5. $\mathrm{Ng}=$ total number of plants in the network.

NB:

1. $T=1$ for DEES

2. $\mathrm{T}>1$ for DEED

B. Constraints

1. Power balance constraint

In an electrical energy production system, demand and losses must be compensated at all times by all the production units in operation of this system. This is translated by the equation:

$$
\sum_{i=1}^{N_{g}} P_{i, t}-P_{D, t}-P_{L, t}=0
$$

Where $P_{D, t}$ is the power demanded in MW at the interval t.

2. Constraints related to the production limits of each generation unit

$$
\begin{gathered}
P_{i}^{\min } \leq P_{i, t} \leq P_{i}^{\max } \\
i \in N_{g}, t \in T
\end{gathered}
$$

Where $P_{i}^{\min }$ and $P_{i}^{\max }$ represent the minimum active power and the maximum active power that the power plant can produce $\mathrm{i}$.

3. Ramp constraints

$$
\left\{\begin{aligned}
\boldsymbol{P}_{i, t}-P_{i, t-1} & \leq U R_{i}, \text { si } P_{i, t}>P_{i, t-1} \\
P_{i, t-1}-P_{i, t} & \geq D R_{i}, \text { si } P_{i, t}<P_{i, t-1} \\
i & \in N_{g} ; t \in T
\end{aligned}\right.
$$

Where $D R_{i}$ and $U R_{i}$ represent the ramp-down and rampup limits of the plant $\mathrm{i}$.

4. DEE Algorithm in the Presence of Statcom

To solve the problem of DEES or that of DEED, the proposed approach can be represented through the following stages:

Step 1: find the ideal position of STATCOMs in the network by multi-objective optimization

Step 2: make the network power flow with the STATCOMs positioned at the nodes determined in step 1

Step 3: calculate the coefficients of the matrix B from the results of the power flow obtained in step 3

Step 4: optimize DEE by U-NSGA-III

Step 4-1: read the data, namely matrix B, number of generators, generator limits, ramp constraints, power demand per hour, production cost coefficients and emission coefficients

Step 4-2: application of U-NSGA-III

1. Initialization of variables

2. Crossing

3. Mutation

4. Selection

5. non-dominated sorting

Step 4-3: show the results

\section{Results}

The U-NSGA-III algorithm has been implemented under MATLAB. The tests were then carried out on the CEB's interconnected network. The CEB's transmission network is a mesh network of 43 nodes and 57 branches. It has six (06) power plants, including three hydroelectric.

A. Results of optimal positioning of STATCOM

Figure 2 presents the voltage profile before the optimal positioning of the STATCOMs.

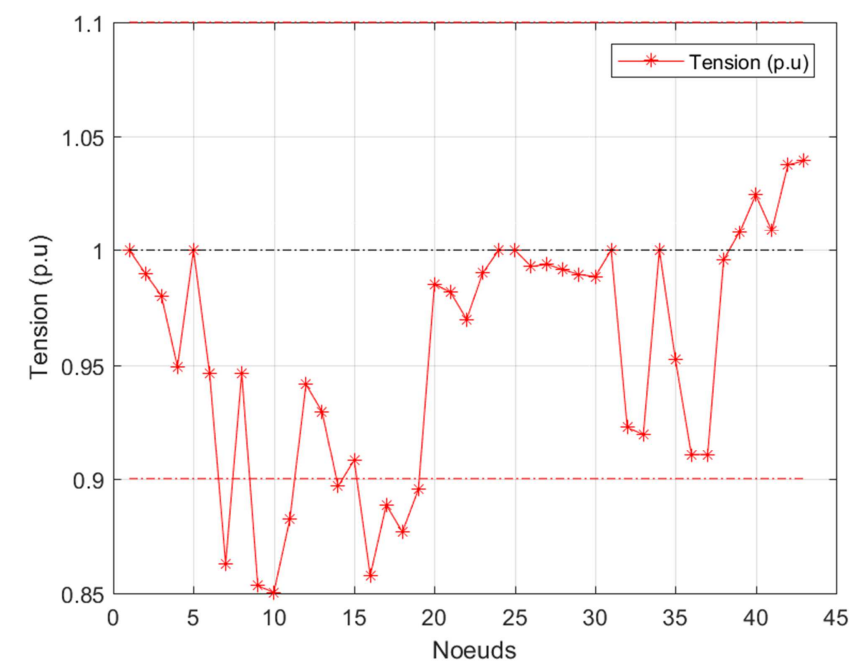

Figure 2. Voltage profile of the CEB's interconnected network before optimal insertion of STATCOM.

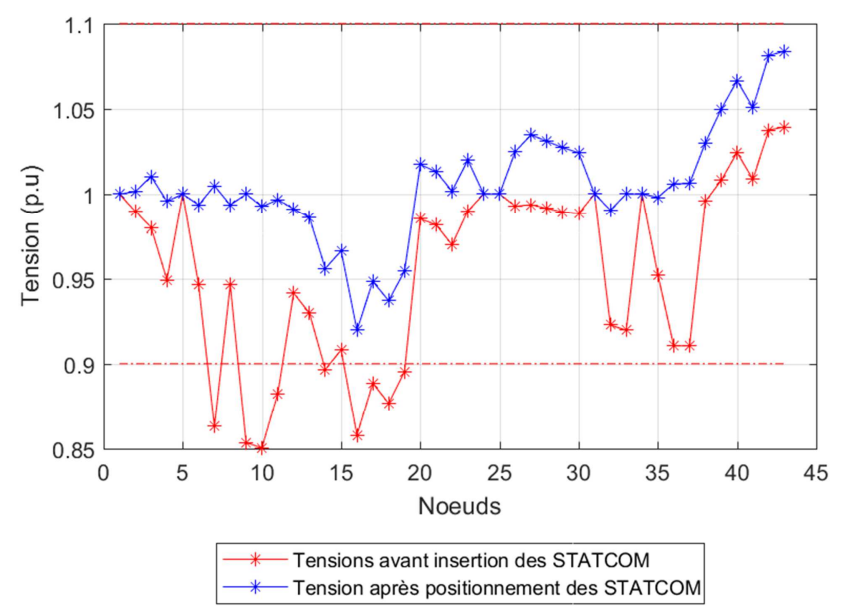

Figure 3. Voltage profile before and after optimal positioning of the STATCOMs. 
According to CEB standards, the voltage values at the various bus bars must be $(1.0 \pm 0.1) \mathrm{pu}$. On this basis, we can see from Figure 2 that there are a total of nine (09) nodes whose tension values are located outside the normative ranges of tension. The calculated voltage deviation is 0.21 whereas it must be as close as possible to zero (00). At the level of lines and transformers, the total active losses calculated are $20.886 \mathrm{MW}$.

After executing the optimal STATCOM placement program, we have obtained the tension profile in figure 3. This figure shows the optimal tension profiles before and after insertion of the STATCOMs.

The optimal positioning of the STATCOMs allowed the installation of two STATCOMs in this network, one of size
58.26 MVar at node 9 and the other of size 104.08 MVar at node 33 . With these positions, the voltage profile of network has improved significantly; the voltage deviation went from 0.208 before placement to 0.048 after optimal placement of the two STATCOMs. The number of unstable nodes went from 09 before placement to 00 after the optimal placement of the two STATCOMs.

\section{B. DEES results}

After having found the ideal location of the STATCOMs and making the power flow of the network, the determination of the coefficients of the matrix B was carried out.

The execution of the DEES optimization program in three cases produced the results in Table 1 .

Table 1. Results of the various DEES optimization cases.

\begin{tabular}{llll}
\hline & Before DEES & After DEES & After DEES + STATCOM \\
\hline Production cost $(\$ / \mathrm{h})$ & 12087.56 & 10807.53 & 10057.40 \\
$\mathrm{CO}_{2}$ emissions in $\mathrm{kg} /$ & 190.30 & 272.97 & 225.53 \\
Active losses in MW & 20.89 & 19.97 & 17.93 \\
\hline
\end{tabular}

Through this table, we notice that the optimization of DEES makes it possible to reduce the total cost of production and the active losses in the network. And when this optimization of the DEES is carried out after improvement of the state of the network by STATCOMs, the reductions in the cost of production and losses are even more pronounced. On the other hand, when these two parameters are reduced, it often happens that the $\mathrm{CO}_{2}$ emissions undergo a slight increase as observed in our current case.

\section{DEED results}

The execution of the DEED optimization program in three cases produced the results in Table 2 .

In our case, the time period considered for DEED is 24 hours. The results of dispatching before optimization and after optimization with and without STATCOM are presented in Table 2.

Table 2. Results of the various DEED optimization cases.

\begin{tabular}{llll}
\hline & Before DEED & After DEED & After DEED + STATCOM \\
\hline Production cost $(\$ / \mathrm{h})$ & $195,376.23$ & $155,360.20$ & $145,043.78$ \\
$\mathrm{CO}_{2}$ emissions in $\mathrm{kg} /$ & $1,428.21$ & $1,533.43$ & $1,422.95$ \\
Active losses in $\%$ & 3.37 & 3.29 & 2.81 \\
\hline
\end{tabular}

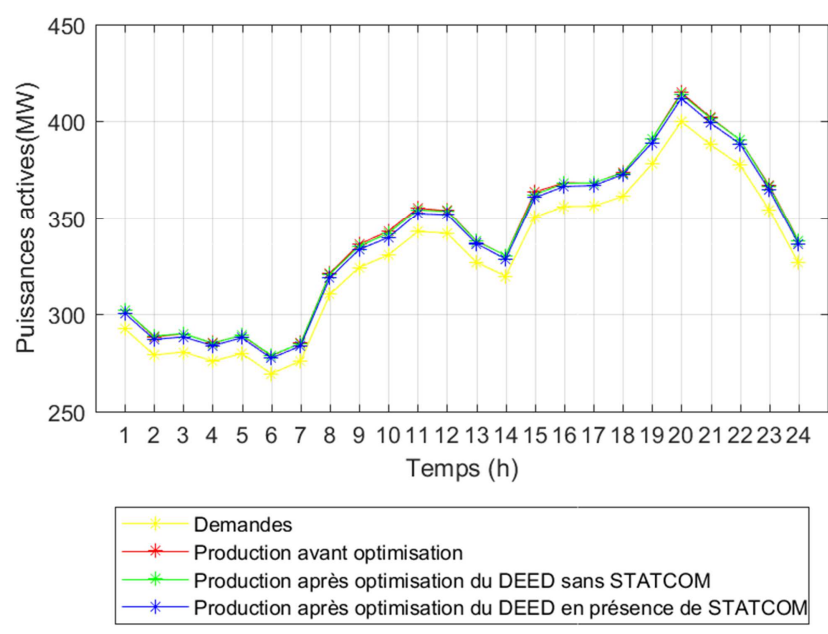

Figure 4. Evolution of demand and production before and after the optimization of DEED.

Analysis of this table shows that the optimization of DEED allows a better distribution of production at plant level according to the production cost, $\mathrm{CO}_{2}$ emissions and active losses in the network objectives. In addition, with the insertion of the two STATCOMs at nodes 9 and 33, the results obtained are clearly better. At all times of the day, the active powers distributed are within their permitted ranges. No power plant is forced to produce more than its maximum capacity or less than its minimum capacity. Security constraints are also checked. At any time, the power generated is equal to the demand plus the active losses in the network; there is no excess production (Figure 4).

Figure 4 shows the evolution of demand and production in the three cases considered.

From this figure, we can easily see that production is always above demand. In addition, the production after optimization of DEED in the presence of STATCOM is always lower than that obtained in the case before optimization and the case of optimization of DEED without STATCOM. This is explained by the fact that by making an optimal DEED, one produces the strict necessary and moreover, with the clear reduction of the active losses in the network (see figure 5) after the insertion of the STATCOM, the production is still more reduced.

In this figure (Figure 5), we note that at each hour of the day, the active loss is always lower in the case of optimization of DEED in the presence of STATCOM than in 
the case before optimization and the case of DEED optimization without STATCOM. In these three cases, the maximum loss is obtained at 20 hours (time when the load is maximum). It is worth $11.98 \mathrm{MW}$ in the case of optimization of DEED in the presence of STATCOM while it is worth 14.09 MW in the case of optimization of DEED without STATCOM and 14.97 MW in the case before optimization.

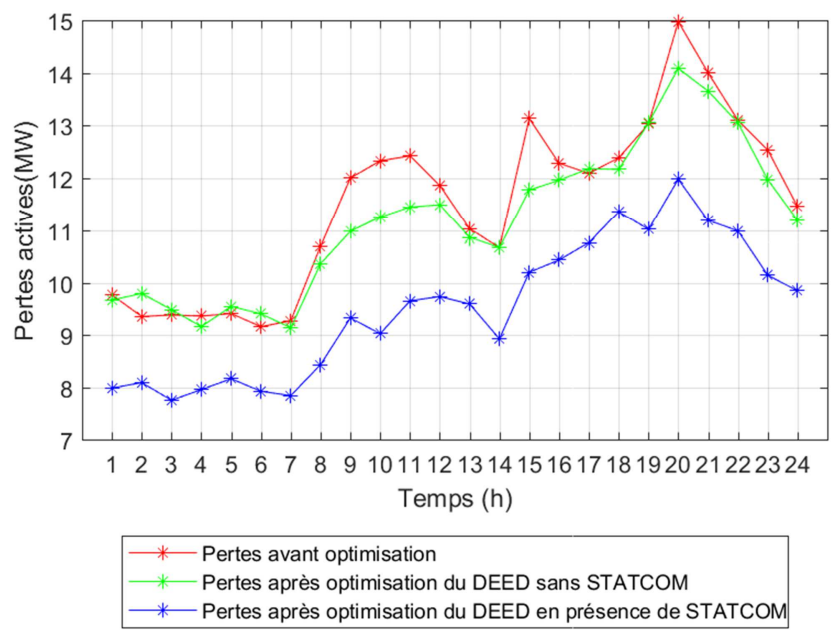

Figure 5. Change in active losses before and after optimization of DEED.

Figure 6 presents the evolution of the total cost of production before (typical CEB dispatching) and after the optimization of DEED.

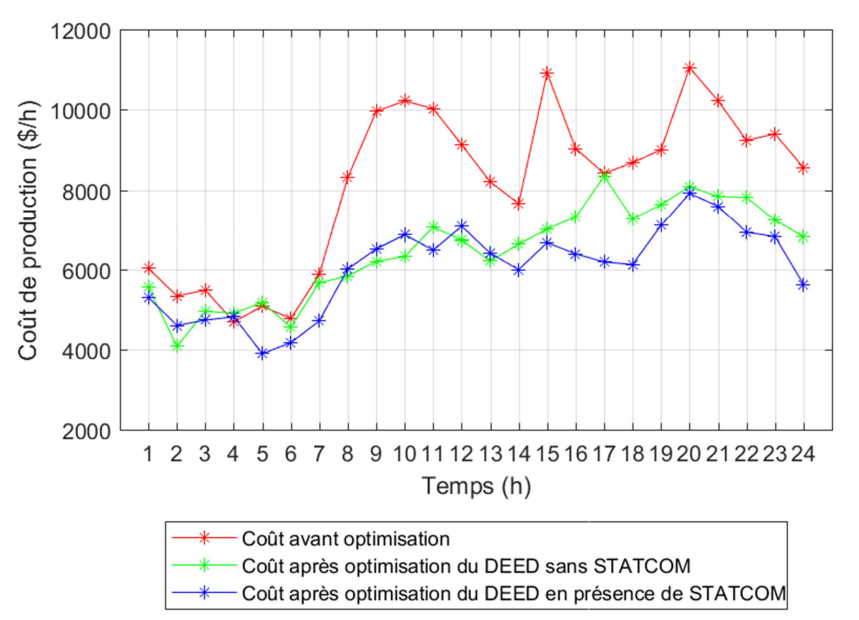

Figure 6. Variation in production cost before and after optimization of DEED in the presence of STATCOM.

Analysis of this graph shows that after the optimization of DEED in the presence of STATCOM, the hourly production cost has reduced considerably. The maximum of this cost is obtained at 8 p.m. in the case before optimization and in the case of DEED optimization in the presence of STATCOM while it is obtained at 5 p.m. in the case of DEED optimization without STATCOM. The maximum production cost in the case of optimization of DEED in the presence of STATCOM is lower than that obtained in the other two cases.

With regard to the change in $\mathrm{CO}_{2}$ emissions after the optimization of DEED in the presence of STATCOM, Figure 7 shows the change in $\mathrm{CO}_{2}$ emissions before and after the optimization of DEED.

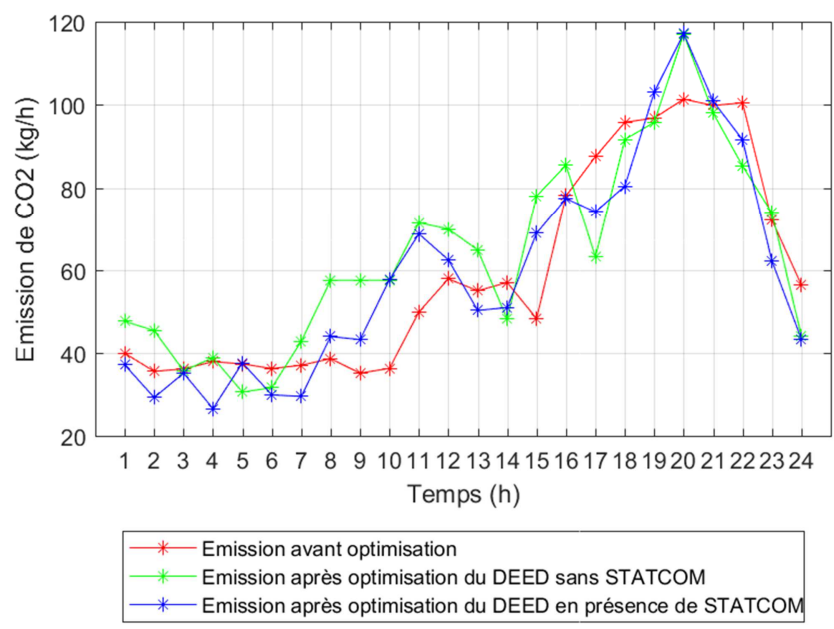

Figure 7. Variation in $\mathrm{CO}_{2}$ emissions before and after the optimization of DEED.

Indeed we notice that from one hour to another, sometimes the emission is greater in the case of the optimization of DEED in the presence of STATCOM than in the case before optimization. Sometimes the opposite happens. Thus, for example, from $1 \mathrm{am}$ to $7 \mathrm{am}$, the $\mathrm{CO}_{2}$ emissions in the case before optimization are higher than those obtained in the case of the DEED optimization in the presence of STATCOM. And from 8 a.m. to 12 p.m., the opposite phenomenon takes place. This is explained by the fact that from 1 am to $7 \mathrm{am}$, demand was decreasing. So even by producing more costeffective power plants, emissions are much lower in the case of DEED optimization in the presence of STATCOM than in the case before optimization. However, from 8 a.m. until 12 p.m. demand increases.

However, overall, the $\mathrm{CO}_{2}$ emissions in the case of DEED optimization in the presence of STATCOM are lower than in the case before optimization; they are respectively $1,422.95$ $\mathrm{kg} / \mathrm{h}$ and $1,428.21 \mathrm{~kg} / \mathrm{h}$ for the 24-hour period considered.

Table 3 presents a summary of the various results obtained during this study.

Table 3. Summary of the results of the various optimizations.

\begin{tabular}{lllllll}
\hline & Before & DEES & DEES + STATCOM & Before (24h) & DEED & DEED + STATCOM \\
\hline Losses $(\%)$ & 4.08 & 3.91 & 3.52 & 3.37 & 3.29 & 2.81 \\
Production cost $(\$ / \mathrm{h})$ & $12,087.56$ & $10,807,528$ & $10,057.4$ & $195,376.23$ & $155,360.20$ & $145,043.78$ \\
Emissions $(\mathrm{kg} / \mathrm{h})$ & 190,296 & 272,973 & 225,526 & $1,428.21$ & $1,533.43$ & $1,422.95$ \\
Unstable knots & 09 & 09 & 00 & 09 & 09 & 00 \\
\hline
\end{tabular}


With regard to this table, we can deduce that the installation of STATCOM followed by the installation of DEED in the interconnected network of the CEB induces an improvement in the performance of this network and makes it possible to satisfy the daily demand for electrical energy at costs reduced and emissions reduced. DEED in the presence of STATCOM allowed a reduction in losses of $17.19 \%$ compared to the initial case (state before optimization). Costs were reduced by $25.76 \%$ and emissions were reduced by $0.37 \%$ compared to the initial case. The economic impact of these reductions is enormous; it is quantified in thousands of CFA francs per hour.

Based on the results presented in Tables 1 and 2, we note that with DEED we have a global planning of the production of electrical energy while with DEES, planning is only obtained for a specific instant. Furthermore, overall, DEED allows a reduction of all the parameters considered (total production cost, $\mathrm{CO}_{2}$ emissions, active losses) whereas with DEES, only two of these three parameters manage to be reduced. DEED is more precise than DEES. It provides, for each hour of the period considered ( 24 hours in our case), the ideal distribution of the production of electrical energy at the level of the power stations for an optimal minimization of the parameters (production cost, $\mathrm{CO}_{2}$ emission, active losses). Therefore, instead of doing DEES every moment of a day, it is better to do DEED with the forecast of loads for that day.

\section{Conclusion}

The performances of STATCOM in improving the results of the optimization of DEE were discussed in this work. The positive impact of STATCOM on the voltage profile has been illustrated graphically. The feasibility of the proposed method was tested on the CEB's interconnected network composed of 43 knots and 57 branchs. From the results obtained, it can be noted that the optimization of DEED in the presence of STACOM in a transmission network contributes to significantly minimize the total production cost, toxic gas emissions and losses and to improve the voltage profiles of the bus bars. Then, with the optimization of DEED in the CEB's transmission network, active losses were reduced of $17.19 \%$. The total cost of production has been reduced by $25.76 \%$ and $\mathrm{CO} 2$ emissions have been reduced by $0.37 \%$ (i.e around 1.8 tonnes/year). This project has a very interesting benefit-cost ratio and may well be the subject of a detailed financial study to serve as decision-making tools for donors.

\section{References}

[1] Khamed OKBA. Dispatching économique dynamique des réseaux électriques par les méthodes méta-heuristiques. Mémoire de Master en réseaux électriques, Université Mohamed Khider Biskra, 2013.
[2] E. Ntom MENTSOUGA, Salomé NDJAKOMO, D. E. Mbadjoun WAPET, and Ngoffe S. PERABI. Dispatching économique et environnemental par une approche du réseau de neurones de hopfield combinée à la méthode de dichotomie. Sciences, Technologies et Développement, Edition spéciale, 17: 147-150, Juillet 2016 https://www.researchgate.net/publication/306056042.

[3] M. A. ABIDO. Environmental/economic power dimatch using multiobjective evolutionary algorithms: A comparative study. AIEE Transactions, pages 920-925, 2003.

[4] ZEGGAR SEIF-EDDINE, «Dispatching Economique D'Energie Electrique Par Essaims De Particules Et Algorithmes Génétiques», thèse de master, Université de Constantine I, 2013.

[5] L. H. WU, Y. N. WANG, X. F. YUAN, and S. W. ZHOU. Environmental/economic power dispatch problem using multiobjective differential evolution algorithm. Electric Power Systems Research, 80: 1171-1181, May 2010. doi: 10.1016/j.epsr.2010.03.010.

[6] Shanhe JIANG, Zhicheng JI, and Yanxia SHEN. A novel hybrid particle swarm optimization and gravitational search algorithm for solving economic emission load dispatch problems with various practical constraints. Electrical Power and Energy Systems, 55: 628-644, 2014. http://dx.doi.org/10.1016/j.ijepes.2013.10.006.

[7] Ngoffe Stève PERABI, Imano Adolphe MOUKENGUE, Essiane Salomé NDJAKOMO, and Ondoa Grégoire ABESSOLO. Résolution du problème d'engagement d'unités de production d'énergie électrique, de dispatching économique et environnemental sélectif par la méthode des couloirs d'observations. Afrique SCIENCE, 11: 74-85, 2015.

[8] A. OLOULADE, A. MOUKENGUE IMANO, F. FIFATIN, S. GANYE, R. BADAROU, A. VIANNOU, H. TAMADAHO. Optimal Placement of an Unified Power Flow Controller in a Transmission Network by Unified Non Dominated Sorting Genetic Algorithm-III and Differential Evolution Algorithm. International Journal of Electrical Components and Energy Conversion. 5. 10-19. DOI: $10.11648 / j . i j e c e c .20190501 .13$.

[9] A. OLOULADE, A. MOUKENGUE IMANO, A. VIANNOU, and $H$. TAMADAHO. Optimisation multi-critère du placement d'un d-statcom dans un réseau de distribution par les colonies de fourmis. SYMPOSIUM DE GENIE ELECTRIQUE, july 2018.

[10] Chintalapudi V. SURESH, S. SIVANAGARAJU, and Rao J. VISWANATHA. Multi-area multi-fuel economic-emission dispatch using a generalized unified power flow controller under practical constraints. Arab J Sci Eng, december 2014. DOI: $10.1007 / \mathrm{s} 13369-014-1527-3$.

[11] S. VIJAYARAJ and R. K. SANTHI. Multi-area economic dispatch with gupfc using improved bat algorithm. Asian Journal of Applied Sciences, 04 (05): 1217-1242, october 2016.

[12] Sekharan SREEJITH and Simon P. SISHAJ. Cost benefit analysis on sve and upfe in a dynamic economic dispatch problem. International Journal of Energy Sector Management, 8 (3): 395-428, 2014. http://dx.doi.org/10.1108/IJESM-052013-0010. 
[13] Sekharan SREEJITH, Velamuri SURESH, and P. PONNAMBALAM. Static economic dispatch incorporating upfc using artificial bee colony algorithm. pages $757-769$, 2016.

[14] P. ACHARJEE. Optimal power flow with upfc using security constrained self-adaptive differential evolutionary algorithm for restructured power system. Electrical Power and Energy Systems, 76: 69-81, 2016. http://dx.doi.org/10.1016/j.ijepes.2015.09.025.

[15] Léré Mitterand DEGUENON, Optimisation de la marge de stabilité de tension d'un réseau électrique par insertion de DFACTS à l'aide du NSGA-II: cas du départ de Cotonou 4, mai 2018.
[16] Garima Choudhary et al., Optimal placement of STATCOM for improving voltage profile and reducing losses using crow search algorithm, International Conference on Control, Computing, Communication and Materials, 2016, doi: 978-14673-9084-2/16.

[17] A. OLOULADE, Contribution à l'optimisation multicritère du fonctionnement d'un réseau électrique de distribution par le placement optimal de dispositifs FACTS et la reconfiguration de sa topologie, Thèse de doctorat soutenu publiquement le 10 Décembre 2019, Université d'Abomey-Calavi. 